\title{
Descarte sustentável de pneus inservíveis
}

\section{RESUMO}

Este trabalho apresenta como objetivo abordar o processo de coleta e reciclagem de pneus inservíveis no Brasil, juntamente com a verificação das ações desenvolvidas pelos fabricantes de pneus após a criação da Política Nacional de Resíduos Sólidos. A verificação da evolução do percentual de pneus reciclados e o papel dos pontos de coleta para o crescimento deste segmento econômico. A fundamentação teórica foi construída retratando conceitos e características da sustentabilidade, juntamente com a legislação vigente a respeito do tema e inter-relacionando com a logística reversa dos pneus inservíveis no Brasil ao longo dos anos. A metodologia foi desenvolvida a partir de um estudo de caso da empresa Reciclanip, abordando as ações da empresa para o crescimento da reciclagem de pneus e também a realização de uma análise da importância dos pontos de coleta para o cumprimento da legislação vigente. Os resultados evidenciam que houve um aumento do percentual de pneus reciclados no Brasil desde o estabelecimento da Política Nacional de Resíduos Sólidos (PNRS). O processo de coleta se dá a partir de 824 pontos e a reciclagem compreende as etapas de coprocessamento, laminação, criação de artefatos de borracha e asfalto de borracha. No ano de 2013, o Brasil atingiu $95 \%$ da destinação adequada dos pneus inservíveis, tendo sido fixado como meta o recolhimento de 479.429,60 toneladas de pneus e verificada uma destinação de 459.030,18 toneladas. Portanto, é possível concluir que há uma conscientização e uma melhoria dos indicadores, o que pode estar associado a Lei no 12.305/10, que institui PNRS.

Palavras-chave: Sustentabilidade. Logística reversa. Descarte sustentável.

Marco Antonio Floriani
Mestrando em Administração
Serviço Nacional de Aprendizagem Comercial (SENAC/SC) - Brasil
marco.floriani@prof.sc.senac.br
Vinícius Cadore Furlanetto
Mestrando em Administração
Serviço Nacional de Aprendizagem Comercial (SENAC/SC) - Brasil
viniciuscfurlanetto@gmail.com
Simone Sehnem
Doutora em Administração
Universidade do Oeste de Santa Catarina (UNOESC) - Brasil
simone.sehnem@unoesc.edu.br




\section{INTRODUÇÃO}

Apesar de ser muito útil desde sua criação, o pneu sempre foi um problema para o meio ambiente. Porém, a partir dos anos 90, com o aumento progressivo da utilização de carros e caminhões é que o Brasil percebeu o grande impacto ambiental causado pelo descarte dos pneus, que após atingir o desgaste completo, ele se torna inservível. O Brasil encontra um grande desafio para dar finalidade correta aos pneus em seu território. De acordo com a Associação Nacional da Indústria de Pneumáticos (ANIP, 2014), foram produzidos mais de 68 milhões de pneus em 2014 no Brasil e comercializados aproximadamente 75 milhões neste mesmo ano. Em 2001 segundo reportagem do site Ambiente Brasil (2001) mais de 40\% dos pneus produzidos eram descartados sem controle e esse descarte pode causar danos à saúde humana caso ocorram incêndios nos locais de descarte. A fumaça resultante contém poluentes que podem afetar o bem-estar físico e psicológico das pessoas (CHEN et al., 2009).

Para Horner (1996), a poluição resultante da decomposição de resíduos de pneus possui metais pesados como chumbo, cádmio e zinco que vazam para o solo causando um estresse perigoso para o ambiente. $\mathrm{O}$ controle do descarte de pneus evoluiu muito no decorrer dos anos devido à preocupação dos fabricantes e também dos recicladores. Informações divulgadas pela Associação Nacional da Indústria de Pneumáticos (ANIP,2014), apontam que no primeiro semestre deste ano o Brasil bateu recorde de reciclagem de pneus, sendo mais de 223 mil toneladas, o que equivale a algo entorno de 45 milhões de pneus de automóveis. Estes números só são possíveis porque em 1999 foi iniciada uma proposta de regulamentação dos resíduos sólidos no Brasil, através da Política Nacional de Resíduos Sólidos (PNRS), que provocou uma mudança na postura do Conselho Nacional do Meio Ambiente (CONAMA) em relação à normatização no tratamento dos resíduos. Um trabalho iniciado em 1998 pelo CONAMA regulamentou o tratamento dos resíduos de diversos produtos, dentre eles: pilhas, pneus, baterias, lâmpadas fluorescentes, entre outros.

Em 2010 após a aprovação da Política Nacional de Resíduos Sólidos (PNRS), os fabricantes, comerciantes, distribuidores, e importadores destes produtos passaram a ser obrigados a desenvolver um sistema de logística reversa no final da vida útil e ainda regulamentou que a responsabilidade da gestão dos resíduos é de responsabilidade de todos os envolvidos: empresas, sociedade e governos em todas as esferas (BRASIL, 2010). Procurando atender a legislação vigente, foi implantado em 1999 pela Associação Nacional da Indústria de Pneumáticos (ANIP) o Programa Nacional de Coleta e Destinação de Pneus Inservíveis no Brasil, a fim de cumprir com a norma estabelecida pelo CONAMA. Em 2007 este programa foi aperfeiçoado pelas fabricantes de pneus novos Bridgestone, Goodyear, Michelin e Pirelli através da criação da Reciclanip, uma entidade voltada à coleta e destinação correta de pneus inservíveis no Brasil. Esta coleta ocorre com parceria de distribuidores, revendedores e prefeitura através da criação e implantação de centros de recepção destes pneus, os chamados Ecopontos (RECICLANIP, 2015).

Segundo a Reciclanip (2015), estavam operando no Brasil 824 Ecopontos e em 2015, de acordo com levantamentos feitos no site da entidade, estão disponíveis 817 endereços de coleta. Isso mostra uma considerável evolução, mas quando comparado ao número de municípios do Brasil, esse número de pontos ainda é muito pequeno. Observando este cenário, principalmente com o crescimento do número de veículos transitando pelas estradas brasileiras, a necessidade de aumentar o volume de pneus inservíveis recolhidos e destinados corretamente para reciclagem. Baseado nessa realidade surge à indagação que motivou a realização deste estudo: o trabalho desenvolvido pela Recliclanip desde sua criação tem causado um impacto significativo na diminuição do destino incorreto dos pneus inservíveis no território nacional?

Este estudo de caso tem por objetivo geral apresentar as ações desenvolvidas pela empresa Reciclanip na destinação de pneus inservíveis no Brasil. Como objetivo específico pretende analisar a evolução destes números desde a instituição da entidade e o atual cenário existente no Brasil e descrever as ações que estão sendo feitas para melhorar os índices em um futuro próximo. O estudo tem sua relevância social baseada no conhecimento das ações que estão sendo realizadas para garantir a diminuição da poluição deixada pelos pneus inservíveis, que são descartados de forma indevida e que provocam doenças à população e poluição do meio ambiente. E ainda serve como impulsionador para que as empresas e os governos se preocupem com a coleta destes resíduos, evitando o destino incorreto. A justificativa prática que motiva a realização 
deste estudo é demonstrar a evolução da destinação correta dos pneus inservíveis no Brasil e incentivar as empresas que fazem parte da cadeia de distribuição e comercialização deste produto para que busquem criar novos pontos de coleta regionalizados a fim de atender ao maior número de municípios, aumentando o percentual de pneus coletados e corretamente destinados à reciclagem.

A justificativa teórica para a realização desta investigação está associada ao que Elkington (2001) salienta que as mudanças mundiais estão fazendo com que a sociedade molde-se para buscar a sustentabilidade através da transformação dos valores humanos, econômicos e sociais com a amplitude do ciclo de vida dos produtos. A estrutura do artigo contempla uma seção teórica que aborda as temáticas sustentabilidade e desenvolvimento sustentável, tratamento de resíduos e sua legislação, logística reversa, reciclagem de pneus e por fim a respeito dos pontos de coleta de pneus inservíveis. A seção 3 descreve a metodologia do estudo, que descreve o caminho que foi percorrido para desenvolver essa investigação. A seção 4 apresenta e analisa dos dados. A seção 5 descreve as considerações finais e sugestões para pesquisas futuras e ainda são apresentadas as referências acessadas para construir este artigo.

\section{FUNDAMENTAÇÃO TEÓRICA}

Para melhor compreensão da temática abordada, são tratados os temas: sustentabilidade, desenvolvimento sustentável, tratamento de resíduos sólidos, legislação vigente no Brasil (que determina as responsabilidades sobre a destinação correta de pneus inservíveis), logística reversa, reciclagem de pneus e a estrutura/funcionalidade dos pontos de coleta.

\subsection{Sustentabilidade e Desenvolvimento Sustentável}

O mundo industrial, durante a década de 50 e 60 produziu excessivo número de produtos de desejo resultando no consumo em massa e em hábitos de descarte indiscriminados. Isso levou ao esgotamento de recursos naturais finitos, a criação de resíduos perigosos e por consequência a poluição do planeta (FERREIRA et al, 2011). Conforme Leite, Araújo e Martins (2011), o aprofundamento da crise ambiental fez com que a sociedade influenciasse no processo de crescimento econômico, pois passou a refletir sobre as questões ambientais e isso levou ao conceito de desenvolvimento sustentável, que surgiu na década de 80 através da relação estabelecida entre a preservação ambiental do planeta e o atendimento das necessidades humanas (IUCN, 1980). Este desenvolvimento, segundo o relatório WCED (1987) satisfaz as necessidades do presente sem comprometer a capacidade das futuras gerações satisfazerem as suas próprias necessidades.

Para Sartori, Latrônico e Campos (2014), o termo Desenvolvimento Sustentável evoluiu como um conceito integrador onde um conjunto de questões inter-relacionadas podem ser organizadas de forma única buscando atender a um único objetivo, a sustentabilidade. Fala ainda que o termo sustentabilidade foi adotado inicialmente pelo movimento ecológico para atender aos recursos renováveis. Conceito esse que se refere à existência de condições ecológicas para dar suporte à vida humana. O conceito de Triple Bottom Line foi proposto por Elkington (2001) como uma forma de medir o desempenho organizacional das empresas acrescentando medidas sociais, ambientais e econômicas, isso ampliou as perspectivas de avaliação das mesmas com foco nos três pilares da sustentabilidade.

Desta forma, as empresas, juntamente com governo buscam estabelecer compromissos com a sustentabilidade através do estabelecimento de uma postura colaborativa. A adoção de princípios de sustentabilidade pelas empresas gera um modelo de gestão sustentável que está ligado aos pilares do desenvolvimento sustentável: ecologicamente correto, socialmente justo e economicamente viável (ELKINGTON, 2001). As pressões regulatórias impostas fazem com que as organizações assumam uma visão estratégica para o estabelecimento de vantagens competitivas baseadas nas adequações ambientais, sociais e econômicas (FERREIRA et al, 2011).

De acordo com Theyel (2000), a integração entre gestão produtiva e ambiental não é espontânea e tem foco histórico voltado à garantia de que o descarte dos processos produtivos atenda os padrões regulatórios, fazendo com que a gestão ambiental esteja alheia aos processos de tomada de decisão referente a produção 
e as operações. A discussão a respeito da sustentabilidade é de que ela é feita baseada nos três interesses e sempre buscando que cada um deles seja atendido simultaneamente. Para Moldan, Janouaková e Hák (2012), não existe consenso sobre o desenvolvimento sustentável e a sustentabilidade devido ao fato que a sustentabilidade descreve processos e suas atividades e o desenvolvimento sustentável estaria concentrado nas pessoas e seu bem estar. Para Leite, Araújo e Martins (2011) é preciso pensar em desenvolvimento econômico ao mesmo tempo que se pensa na preservação do meio ambiente e no benefício da sociedade. Leite, Araújo e Martins (2011) afirmam ainda que são necessários modelos de medição de desempenho em sustentabilidade, sem o foco nas medições isoladas de cada dimensão do Triple Bottom Line. Por esse motivo é que as empresas precisam alinhar os processos sustentáveis, principalmente no que diz respeito a redução dos resíduos através da busca da eficiência produtiva. Esta eficiência é fundamental para gerar competitividade com a integração das áreas funcionais das empresas, através de uma gestão voltada a atender todas as dimenções da sustentabilidade de forma eficaz.

\subsection{Tratamento de Resíduos}

No decorrer da história, as indústrias através de suas atividades produtivas poluentes produzem rejeitos nocivos ao meio ambiente. Estes resíduos representam perda de insumos e matérias-primas, o que caracteriza a poluição industrial como desperdício e sinal de ineficiência do processo produtivo (FREIRE et al, 2000).O resíduo sólido pode ser definido como"todo o material sólido ou semi-sólido indesejável e necessita ser removido por ter sido considerado inútil por quem o descarta, em qualquer recipiente destinado a este ato" (IBAM, 2007, p. 25).

De acordo com a Lei №12.305/10 (BRASIL, 2010), que instituiu a Política Nacional de Resíduos Sólidos, o termo "resíduo classifica-se como material, substância, objeto ou bem descartado resultante de atividades humanas em sociedade [...]". Esta mesma lei, no que tange ao gerenciamento dos resíduos sólidos, responsabiliza o poder público, as empresas e a coletividade pela observância e a aplicabilidade da PNRS através de ações que vão da não geração de resíduos, sua redução, reutilização, reciclagem, tratamento e finalmente a disposição final ambientalmente adequada dos rejeitos produzidos no processo. $\mathrm{O}$ artigo 31 da mesma lei, responsabiliza os fabricantes, importadores, comerciantes e distribuidores pela gestão dos resíduos e subsequente destinação final ambientalmente adequada através de um sistema de logística reversa. Este compromisso é gerado com os municípios de acordo com as ações preventivas previstas nos planos municipais de gestão integrada de resíduos sólidos.

\subsection{Legislação no Brasil}

No Brasil, no que se refere à Política Nacional do Meio Ambiente, a Lei nº 6.038/81 delega ao Conselho Nacional do Meio Ambiente - CONAMA a competência do gerenciamento de pneumáticos inservíveis e da edição de atos jurídicos e normativos necessários para a regulamentação e execução das medidas tomadas. Em 26 de agosto de 1999 foi aprovada a Resolução do CONAMA n 258/99, que fixava as metas e obrigava os fabricantes e importadores de pneus a darem destinação final aos pneus inservíveis. Em 26 de agosto de 1999 foi aprovada a Resolução do CONAMA n 258/99, que determinava a obrigatoriedade dos fabricantes e as importadoras de pneumáticos a coletar e dar destinação final ambientalmente adequada aos pneus inservíveis (CONAMA, 1999). Já em 2002 esta Resolução foi alterada (CONAMA, 2002) e em 2009 uma nova resolução de $n^{\circ} \mathbf{4 1 6}$ de 30 de setembro revogou as anteriores e passou a dispor sobre a prevenção à degradação ambiental causada por pneus inservíveis e sua destinação ambientalmente adequada (BRASIL, 2009). Além disso, os distribuidores, revendedora, reformadores e consumidores finais ficaram estabelecidos como corresponsáveis pela coleta dos pneus usados.

O Brasil reciclava somente $10 \%$ dos pneus produzidos antes da referida lei ser aprovada. Posteriormente, a aprovação da lei o número de empresas cadastradas para exercer o processo de recolhimento e destruição de pneus cresceu constantemente. Dados de 2010 apresentam que eram 124 empresas cadastradas no IBAMA para a reutilização, reciclagem e valorização energética dos pneus (LAGARINHOS; TENÓRIO, 2013). 
De acordo com Lagarinhos e Tenório (2013) os fabricantes devem elaborar um plano de gestão de coleta, armazenamento e destinação final dos pneus inservíveis e ainda instalar no mínimo um ponto de coleta nos municípios com mais de 100 mil habitantes. Esta obrigatoriedade possibilita que as grandes cidades brasileiras possuam locais específicos que os pneus inservíveis possam ser destinados, evitando assim o armazenamento e destino inadequado e também possíveis danos ao meio ambiente.

\subsection{Logística Reversa}

O conceito de logística reversa é datado dos anos 70, onde surgiram definições como canais reversos ou fluxos reversos, principalmente relativos à reciclagem. No Brasil o termo relacionado as empresas surgiu na década de 90 e estava atrelado a logística através das matérias-primas, componentes e suprimentos que representavam custos significativos e que deveriam ser administrados de forma adequada, quando do seu retorno de pós-venda ou pós-consumo (LAGARINHOS; TENÓRIO, 2013). O Council of Supplier Chain Management Professionals (2013) define a logística reversa como um segmento especializado de logística com foco na movimentação e gestão de produtos e recursos após a venda e após a entrega ao cliente. Inclui devoluções de produtos para o reparos e/ou créditos. Para Leite, Araújo e Martins (2011) a logística reversa planeja, opera e controla o fluxo e as informações logísticas correspondentes, do retorno dos bens de pré e pós-venda e pós-consumo ao ciclo de negócios ou ao ciclo produtivo.

A fim de que os custos envolvidos na coleta dos produtos descartados seja reduzido, recomenda-se que as empresas responsáveis pela coleta, sejam elas fabricantes, distribuidores, comerciantes forneçam pontos de coleta, com localização centralizada (KWATENG et al, 2014). A logística reversa nasce principalmente no momento em que evidencia-se um aumento da população, atrelado ao aumento significativo do consumo e por consequência a industrialização através do uso de embalagens destacáveis desencadearam uma preocupação com a destinação correta destes resíduos após o consumo.

Segundo Tepprasit e Yuvanont (2015) com a preocupação sobre o meio ambiente aumentando, mais e mais países promulgam leis a fim de minimizar o impacto ecológico da logística e que está relacionado às alterações climáticas, poluição do ar, resíduos, entre outros. Na cadeia de reciclagem, a logística reversa é um dos principais processos e que viabiliza economicamente toda a cadeia, seja no processo de reutilização, reciclagem ou valorização energética. Isso permite que as empresas façam o melhor do ponto de vista econômico, ambiental e da comunidade (TEPPRASIT; YUVANONT, 2015). No caso dos pneus, este processo se torna desafiador no que diz respeito à viabilidade econômica, pois o seu transporte desde os pontos de coleta até os locais de reciclagem se torna elevado não sendo vantajoso para a indústria, distribuidores e comerciantes (CHAN; CHAN; JAIN, 2012).

\subsection{Reciclagem de Pneus}

Segundo Rodrigues e Henkes (2015), a ideia de reutilização de pneus é muito antiga, mas sua ação se deu somente após a Segunda Guerra Mundial devida a dificuldade na obtenção de matéria-prima para a produção de pneus novos. Os pneus, quando trocados por novos, são descartados após o término de sua vida útil. Este descarte pode ocorrer em empresas que realizam a troca dos usados pelos novos ou muitas vezes o consumidor descarta estes pneus em rios, aterros e até mesmo em locais de coleta de lixo comum. A destinação final adequada do pneu é de responsabilidade de todos, consumidores, fabricantes, distribuidores, revendedores e importadores (BRASIL, 2009). O destino correto trará benefícios à saúde pública e ao meio ambiente.

Para Roy, Nollet e Beaulieu (2006), a reciclagem de pneus não traz nenhum lucro para os fabricantes de pneus, pois, o governo não pensou em internalizar os custos aos fabricantes, mas sim, encontrar uma solução para a crise ecológica que o setor estava passando e contribuir para o desenvolvimento da reciclagem de pneus inservíveis como um novo setor industrial. As formas de reciclagem dos pneus pode ser feita de diversas formas, desde a utilização de sua carcaça até mesmo a trituração para utilização na produção de diversos produtos e materiais. A avaliação dos pneus para destinação correta, passa por uma triagem das 
carcaças e se estas possuírem condições de serem utilizadas, são encaminhadas a empresas especializadas na recauchutagem, remoldagem ou a recapagem (RESENDE, 2004). Segundo Chan, Chan e Jain (2012), no mercado internacional, os pneus em boas condições são vendidos ou exportados.

Os pneus que não apresentam condições de reutilização são encaminhados a empresas de reciclagem para que sejam triturados e, posteriormente, os materiais formados são destinados de acordo com sua utilização. Conforme afirmam Bertollo e Fernandes Júnior (2002), o processo de reutilização dos pneus inservíveis possui um alto custo devido ao processo de corte e trituração pelo qual é passado a fim de separar e permitir a recuperação de materiais inicialmente utilizados em sua fabricação. A borracha extraída pela trituração dos pneus inservíveis pode ser reaproveitada para a confecção de chinelos, tapetes automotivos, pisos industriais, solas de sapato, borrachas de vedação, quadras esportivas, na composição de asfalto e concreto e também como matriz energética em indústrias cimenteiras (RECICLANIP, 2015).

\subsection{Pontos de Coleta}

Devido à exigência da legislação, em que as empresas fabricantes, importadoras e distribuidoras foram obrigadas a dar destino correto aos pneus inservíveis e também da obrigatoriedade da instalação por parte das fabricantes e importadoras, em cidades acima de 100 mil habitantes de pontos de coleta. Visando atender a esta exigência da legislação é que a Reciclanip criou os chamados Ecopontos. De acordo com Roy, Nollet e Beaulieu (2006), para ser viável a logística de coleta em larga escala, principalmente em áreas de baixa densidade demográfica, faz-se necessário organizar uma rede de transporte envolvendo empresas terceiras com a finalidade de reduzir custos.

Estes Ecopontos são locais disponibilizados por Prefeituras Municipais, para onde são levados os pneus recolhidos pelo serviço municipal de limpeza pública e também diretamente por borracheiros, recapadores, e empresas que comercializam pneus. Estes pontos de coleta possuem normas de segurança e higiene, com cobertura para evitar que os pneus fiquem expostos a chuva (RECICLANIP, 2015). A Reciclanip faz a coleta dos pneus depositados nos Ecopontos quando este atinge a quantidade de 2000 pneus de passeio ou 300 pneus de caminhões e similares e faz a destinação ambiental adequada para empresas destinados licenciadas pelos órgãos ambientais competentes e homologados pelo Instituto Brasileiro de Meio Ambiente (IBAMA) (RECICLANIP, 2015).

\section{METODOLOGIA}

O estudo ora descrito consiste em um estudo documental da empresa Reciclanip, constituída pela Associação Nacional da Indústria de Pneumáticos (ANIP), partindo das responsabilidades impostas pela Resolução no. 416, de 30 de setembro de 2009 do CONAMA - Conselho Nacional de Meio Ambiente. A abordagem da pesquisa é qualitativa e com relação ao enfoque consiste em uma pesquisa descritiva. Quanto aos procedimentos consiste em um estudo de caso que foi operacionalizado por meio de dados secundários. Os dados foram buscados em documentos e no website da empresa. As categorias de análise do estudo foram elaboradas a partir da abordagem do Tripple Bottom Line (TBL) preconizada por Elkignton (2001) e consistem em:

a) Dimensão social: o sistema social deverá estar equalizado, reduzindo suas desigualdades, para possibilitar uma progressão total, do contrário haverá constantemente impactos e rupturas no desenvolvimento ambiental e econômico;

b) Dimensão ambiental: fundamental identificar quais as formas de capital natural impactadas pelas suas operações, avaliar se elas são sustentáveis, se o nível de estresse causado é sustentável e, finalmente, se o equilíbrio da natureza está sendo afetado de forma significativa;

c) Dimensão econômica: uma visão além das barreiras da lucratividade, compreendendo a inserção do capital humano e intelectual, dentro do contexto do capital econômico, com um horizonte de desenvolvimento de longo prazo.

Além dessa análise, o estudo buscou mapear aspectos associados ao volume de resíduos coletados, 
pontos de coleta de pneus e destinação dos materiais coletados. Os dados foram tabulados na forma de tabelas, quadros e ilustrações. A técnica de análise adotada consiste na análise descritiva. De posse dos dados empíricos, foi tecida uma análise à luz da teoria do TBL, buscando resgatar similaridades e discrepâncias existentes entre os preceitos teóricos e os dados mapeados na organização investigada.

\section{APRESENTAÇÃO E ANÁLISE DOS DADOS}

Esta seção descreve a caracterização da organização pesquisada, apresenta o volume de resíduos coletados, os pontos de coleta de pneus e a destinação dos materiais coletados. Além disso, analisa os resultados a luz do arcabouço teórico descrito na seção 2 deste artigo.

\subsection{Caracterização da organização pesquisada}

O estabelecimento das diretrizes ambientais, compreendendo a degradação ao meio ambiente causada pelo descarte irresponsável de pneus inservíveis, foram pilares fundamentais identificados pela ANIP. Este foi o objetivo principal da constituição de uma empresa, focada na logística reversa da cadeia produtiva de pneumáticos. A evolução do segmento até o estabelecimento da empresa é apresentada no Quadro 1.

Quadro 1 - Evolução ANIP

\begin{tabular}{|c|l|}
\hline ANO & \multicolumn{1}{c|}{ DESCRIÇÃO } \\
\hline 1936 & Início das atividades da indústria pneumática brasileira; \\
\hline 1960 & $\begin{array}{l}\text { Fundação da ANIP, entidade sem fins lucrativos, que tem como escopo principal defender } \\
\text { os interesses e objetivos comuns dos fabricantes nacionais de pneumáticos; }\end{array}$ \\
\hline 1990 & Início do Programa Nacional de Coleta e Destinação de Pneus Inservíveis; \\
\hline 2007 & Criação da Reciclanip. \\
\hline
\end{tabular}

Fonte: dados da pesquisa (2015)

A Reciclanip possui características organizacionais fundamentadas no desenvolvimento sustentável, representando atualmente uma das maiores iniciativas da indústria brasileira na área de responsabilidade pós-consumo, tendo sua estrutura comparável aos melhores programas de reciclagem desenvolvidos no país. A estrutura de gestão foi delineada com os argumentos estratégicos na sequencia apresentados.

A missão é administrar o processo de coleta e destinação de pneus inservíveis em todas as regiões, visando:

- Garantir a captação de pneus, por meio da participação de todos os elos da cadeia de produção;

- Assegurar sua autonomia operacional e financeira, reformulando o perfil da entidade de ser o centro de custos para "profit-center"; e tornar-se referência em conhecimento e informação.

A visão é ser uma entidade modelo, autossustentável, reconhecida e admirada pelo trabalho efetivo na destinação de pneus inservíveis e dotada de autonomia operacional e financeira.

Notória a importância e amplitude do tema, legalmente instituído pela legislação brasileira vigente, cabendo à reflexão quanto ao paradigma econômico vinculado ao processo. A sustentabilidade estrutura seu pensamento triple bottomline, para manter o processo reverso da cadeia de abastecimento as indústrias pneumáticas demandaram de grande investimento, fato que possivelmente seria inviável sem a criação de uma entidade compartilhada entre os principais fabricantes. A estratégia de aplicação dos conceitos seguiu pilares especificamente desenhados para colocar o projeto em prática, conforme podemos observar no Quadro 2. 
Quadro 2 - Descrição da estratégia de trabalho Reciclanip

\begin{tabular}{|l|l|}
\hline \multicolumn{1}{|c|}{ AÇÃO } & \multicolumn{1}{c|}{ DESCRIÇÃo } \\
\hline Estruturar & $\begin{array}{l}\text { Estruturar a cadeia de coleta e destinação de pneus inservíveis, com a participação } \\
\text { da rede de revendedores e reformadores, poder público e sociedade, em todo o país; }\end{array}$ \\
\hline Destinar & Destinar de forma ambientalmente adequada os pneus inservíveis disponíveis; \\
\hline Apoiar & $\begin{array}{l}\text { Apoiar estudos e pesquisas sobre o ciclo de vida do pneu, e estimular novas formas } \\
\text { destinação destes pneus inservíveis; }\end{array}$ \\
\hline Desenvolver & $\begin{array}{l}\text { Desenvolver, em conjunto com o poder público, programas e ações de educação } \\
\text { ambiental para a população. }\end{array}$ \\
\hline
\end{tabular}

Fonte: dados da pesquisa (2015)

Um dos pontos principais desenvolvidos pelo modelo está na criação e desenvolvimento dos pontos de coleta dos pneus inservíveis, conhecidos como Ecopontos. Estes locais surgem de parcerias estabelecidas entre a Reciclanip e prefeituras de diversas cidades brasileiras, sendo administrados pelo poder público, que através dos serviços municipais de limpeza pública recolhe o material, efetuando a armazenagem em local devidamente estabelecido e com a infraestrutura necessária. Os pneus destinados voluntariamente, por borracharias, recapeadoras, transportadoras, também são acondicionados nestes locais, aguardando a retirada. Por meio da parceria de convênio, a Reciclanip fica responsável por toda gestão da logística de retirada dos pneus inservíveis do Ponto de Coleta e pela destinação ambientalmente adequada deste material em empresas destinadoras licenciadas pelos órgãos ambientais competentes e homologados pelo lbama.

\subsection{Indicadores do Volume de Pneus Coletados e Pontos de Coleta}

A empresa contabilizou em 2013 um total de 824 pontos de coleta, números crescentes amparados pelo amplo desenvolvimento de acordos com Prefeituras Municipais (Tabela 1).

\begin{tabular}{cc}
\multicolumn{2}{c}{ Tabela 1 - Evolução dos pontos de coleta } \\
\hline ANO & PONTOS DE COLETA \\
\hline 2013 & 824 \\
2012 & 743 \\
2011 & 726 \\
2010 & 578 \\
2009 & 437 \\
2008 & 339 \\
2007 & 270 \\
2006 & 220 \\
2005 & 135 \\
2004 & 85 \\
\hline
\end{tabular}


O estabelecimento dos pontos de coleta é uma ação bastante simples, envolvendo a constituição de um Convênio de Cooperação Mútua, entre a Reciclanip e Prefeitura. O poder público destinará uma área, obrigatoriamente coberta e protegida, para funcionar como depósito dos pneus, sendo efetuado periodicamente o recolhimento dos mesmos pela Reciclanip ou parceiros legalmente autorizados. A ação representa uma ótima iniciativa do poder público, na busca pelo desenvolvimento sustentável para sua região, podendo ainda ampliar a utilização destes pontos, incorporando outros produtos recicláveis e danosos ao meio ambiente em seus projetos municipais. Ressalta-se que existem outros padrões e tipos de coleta de pneus inservíveis no Brasil, legalmente instituídos pelo CTF - Cadastro Técnico Federal, porém não apresentam características de acompanhamento e recolhimento como os caracterizados pela ANIP.

Os pneumáticos coletados podem receber vários destinos, conforme demandas existentes, seu ciclo de vida apresenta etapas claras e definidas, delineando as responsabilidades de toda a cadeia produtiva, conforme se pode observar no Quadro 3.

Quadro 3 - Ciclo de vida do pneu

\begin{tabular}{|l|l|}
\hline \multicolumn{1}{|c|}{ FLUXO } & \multicolumn{1}{c|}{ DESCRIÇÃo } \\
\hline Fábrica & $\begin{array}{l}\text { Responsável direto por toda a cadeia de suprimento } \\
\text { do produto, inclusive sua logística reversa; }\end{array}$ \\
\hline Loja & $\begin{array}{l}\text { Trabalha de forma integrada, como elo para } \\
\text { fechamento do ciclo e correta destinação; }\end{array}$ \\
\hline Reforma & $\begin{array}{l}\text { Oportunizando uma extensão da vida útil do pneu, } \\
\text { com a recapagem e inserção deste novo agente ao } \\
\text { processo; }\end{array}$ \\
\hline Trituração & $\begin{array}{l}\text { Trituração dos compostos de borracha para posterior } \\
\text { reutilização como matéria prima reciclada; }\end{array}$ \\
\hline Coprocessamento & $\begin{array}{l}\text { Aproveitamento do material triturado } \\
\text { transformação em novos produtos; }\end{array}$ \\
\hline Destinação & $\begin{array}{l}\text { Pode ser efetuada a partir do material triturado ou } \\
\text { coprocessado, envolve a reutilização do produto de } \\
\text { forma ambientalmente adequada. }\end{array}$ \\
\hline
\end{tabular}

Fonte: dados da pesquisa (2015)

Os destinos seguem conceitos de sustentabilidade, englobando uma grande diversidade de possibilidades, as principais utilizações estão expressas a seguir:

- Coprocessamento: pelo seu alto poder calorífico, os pneus inservíveis são largamente utilizados como combustível alternativo em fornos de cimenteiras, em substituição ao coque de petróleo;

- Laminação: nesse processo, os pneus não-radiais são cortados em lâminas que servem para a fabricação de percintas (indústrias moveleiras), solas de calçados, dutos de águas pluviais etc.;

- Artefatos de borracha: a borracha retirada dos pneus inservíveis dá origem a diversos artefatos, entre os quais tapetes para automóveis, pisos industriais e pisos para quadras poliesportivas;

- Asfalto-borracha: adição à massa asfáltica de pó de borracha oriundo da trituração de pneus inservíveis. O asfalto-borracha tem uma vida útil maior, além de gerar um nível de ruído menor e oferecer maior segurança aos usuários das rodovias.

Segundo informações apresentadas pelo IBAMA, no ano de 2013 o Brasil atingiu 95\% da destinação adequada aos pneus inservíveis, tendo sido fixado como meta o recolhimento de 479.429,60 toneladas de pneus e verificada uma destinação de 459.030,18 toneladas (IBAMA, 2013). Estas informações são 
disponibilizadas através do Relatório Anual de Pneumáticos emitido pelo IBAMA para acompanhamento da Resolução 416. Este documento apresenta informações valiosas sobre o mercado de pneumáticos, ciclo do produto e sua destinação. Na Tabela 2 podemos visualizar as principais destinações do processo.

Tabela 2 - Destinação dos pneumáticos inservíveis

\begin{tabular}{lcc}
\hline \multicolumn{1}{c}{ Tecnologia } & Destinação (t) & Percentual País \\
\hline Coprocessamento & $267.448,35$ & $54,40 \%$ \\
Granulação & $165.574,82$ & $33,68 \%$ \\
Laminação & $43.839,44$ & $8,92 \%$ \\
Industrialização do Xisto & $14.700,00$ & $2,99 \%$ \\
Pirólise & 72,94 & $0,01 \%$ \\
Regeneração da Borracha & 17,47 & $0,00 \%$ \\
\hline Total & $459.030,59$ & $100 \%$ \\
\hline
\end{tabular}

Fonte: IBAMA (2013)

Outra informação bastante relevante apresentada pelo IBAMA trata da destinação de pneus por regiões brasileiras (Tabela 3). A concentração de descarte nas regiões sul e sudeste pode ser explicada pela maior densidade populacional e atividade econômica encontradas nestas regiões. Como consequência, maior concentração de lixo e necessidade de destinação para materiais danosos ao meio ambiente.

Tabela 3 - Quantidade de pneus inservíveis destinados por região brasileira

\begin{tabular}{|c|c|c|}
\hline Região & Destinação (t) & Percentual País \\
\hline Sudeste & $287.403,89$ & $58,46 \%$ \\
\hline Sul & $117.890,87$ & $23,98 \%$ \\
\hline Centro-Oeste & $48.079,83$ & $9,78 \%$ \\
\hline Nordeste & $29.245,93$ & $5,95 \%$ \\
\hline Norte & $9.032,50$ & $1,84 \%$ \\
\hline Total & $491.653,01$ & $100 \%$ \\
\hline
\end{tabular}

Fonte: IBAMA (2013)

Os impactos de um mercado com estas dimensões, atrelado a um produto com grande capacidade de geração de dano ambiental, permitem uma mensuração da importância do trabalho desenvolvido pela ANIP, com a constituição de uma empresa focada na logística reversa dos pneumáticos. A Reciclanip e seus parceiros, tanto a iniciativa pública como empresas privadas, constituem um elo de sustentabilidade referenciado e estruturado para todo o Brasil. 


\subsection{Ações que estão sendo feitas para melhorar os índices}

Foi possível perceber que as ações que estão sendo desenvolvida pela ANIP para melhorar os índices num futuro próximo são:

- ampliação das parcerias e estruturas de coleta dos pneus inservíveis;

- orientações para desenvolvimento de um "consumidor consciente";

- ampliar o rigor da legislação, abrangendo as importadoras de pneumáticos.

Além disso, recomendam-se algumas outras ações que a empresa pode incorporar para a melhoria dos seus indicadores:

- Incorporar práticas de eco-inovação na gestão dos resíduos derivados de pneus;

- Incorporar práticas de inovação sustentável na cadeia de gestão dos resíduos derivados de pneus;

- Criar redes e clusters entre setores que adotam matéria-prima similar;

- Criar associações pequenas cooperativas localizadas em diferentes territórios brasileiros, para disseminar boas práticas de gestão dos pneus inservíveis;

- Criar práticas de educação ambiental e disseminar nas escolas;

- Criar campanhas de divulgação e premiação dos melhores cases de gestão de pneus inservíveis;

- Fazer parcerias com centros e institutos de pesquisa para desenvolver novas aplicabilidades dos resíduos derivados de pneus;

Portanto, as boas práticas de manejo e gestão dos resíduos derivados de pneus podem ser otimizadas e repensadas. Dessa forma, a efetividade e eficiência da gestão desses resíduos tende a ser maximizada.

\subsection{Análise dos Resultados}

Os dados coletados demonstram o tamanho do problema e potenciais impactos ambientais. A implantação da Resolução 416/2009 do CONAMA amenizou em grande escala estes danos. A Teoria dos Três Pilares de Elkington (2001) apresenta as dimensões econômicas, ambientais e sociais, que trabalhadas de forma sinérgica possibilitam um desenvolvimento pleno e sustentável. A ação da ANIP, na constituição da Reciclanip, proporciona uma visão interessante sobre o tema, cabendo o desenvolvimento de algumas reflexões:

- Dimensão Ambiental: o projeto auxiliou na destinação correta de 459.030,18 toneladas de pneus no ano de 2012, atingindo 95\% da meta estabelecida pelo IBAMA. No ano de 2013 estes números atingiram crescimento superior a 7\%, totalizando 491.653,02 toneladas, porém com retração da meta para $91 \%$. Imaginar esta quantidade de pneus descartados sem responsabilidade remeteria a um potencial problema de saúde pública. Podemos perceber o impacto do trabalho da Reciclanip quando estratificamos, através do relatório do IBAMA (2013), separando os fabricantes de pneus de empresas importadoras. Neste ponto os fabricantes atingiram $106,93 \%$ de sua meta, ou seja, destinaram corretamente mais toneladas de pneus do que o total estabelecido. Já as empresas importadoras obtiveram um atingimento da meta de apenas $62,7 \%$, fatores que reforçam a necessidade de ajustes de nossa legislação e atuação fiscalizadora com maior rigor neste tipo de empresa.

- Dimensão Social: a grande maioria dos pneus destinados segue o caminho do coprocessamento, atingindo um percentual de $54,40 \%$ no ano de 2014 . Considerando que, segundo informações da Votorantim (2015) os sistemas de exaustão de gases de nossas indústrias cimenteiras atingem uma eficiência próxima a 99\%, podemos afirmar que o processo elimina riscos reais de saúde pública. Outro fator interessante é a geração de empregos diretos e indiretos proporcionadas pela coleta, armazenagem e transporte destes pneus, sendo assunto sugerido para futuras pesquisas e mensuração.

- Dimensão Econômica: outra destinação importante é a granulação que atinge 33\% do total de pneus descartados. Este processo garante movimento econômico direto. Segundo informações retiradas do mercado, o preço de $100 \mathrm{~kg}$ de borracha granulada, com espessuras de 2 a $3 \mathrm{~mm}$, pode chegar a $\mathrm{R} \$ 65,00$ (MERCADO LIVRE, 2016). Calculando sobre o total destinado neste método 165.574,82 toneladas (IBAMA, 2013), chegamos a uma receita total de $\mathrm{R} \$ 107.623,63$ (aproximadamente cento e sete milhões de reais) a 
partir do "lixo". Estes números demonstram a importância da logística reversa e os impactos econômicos que podem ser proporcionados por ações sustentáveis.

Estas informações são um recorte da situação atual deste setor, que insere a cada ano 764.668,28 toneladas de pneus novos no mercado (IBAMA, 2013), caminhando de forma consciente para um desenvolvimento sustentável de toda a cadeia produtiva.

\title{
5 CONSIDERAÇÕES FINAIS
}

O aumento do percentual de pneus reciclados no Brasil desde o estabelecimento da Política Nacional de Resíduos Sólidos apresenta uma evolução no processo de logística reversa de pneus inservíveis. Isso mostra que a responsabilidade compartilhada entre as empresas envolvidas no processo de fabricação e comercialização está sendo levada a sério e com as ações que estão sendo implantadas, principalmente pela empresa estudada faz com que a consciência ecológica esteja cada vez mais presente na comunidade em geral.

O aumento da fiscalização, por parte das Prefeituras Municipais e pelos órgãos ambientais, se faz necessário, pois ainda existem muitas empresas que não realizam a destinação correta dos pneus, descartando os mesmos em aterros e até mesmo, deixando ao céu aberto a disposição da população para que usem estes pneus da forma com que melhor convier. Observa-se neste estudo que muito ainda precisa ser feito para que os números de pneus reciclados continuem a crescer. $O$ fato de que existam somente 817 pontos de coleta de pneus inservíveis no Brasil mostra o tamanho do desafio que a Reciclanip, juntamente com as Prefeituras Municipais possuem para melhorar o resultado da reciclagem deste material de forma ambientalmente correta.

Faz-se necessário uma maior divulgação e conscientização entre as empresas distribuidoras e comerciantes de pneus para que mobilizem a criação de pontos de coletas regionalizados, facilitando assim a destinação destes pneus aos centros de reciclagem, aumentando assim o número de pneus recolhidos e destinados corretamente ao processo de reciclagem. Outra ação possível e que poderia ser estabelecida pelo Poder Público, é o incentivo econômico para as empresas que utilizarem compostos de resíduos dos pneus como matéria prima de seus produtos. Esta determinação faria com que estas empresas buscassem o desenvolvimento de pesquisas e tecnologias para o melhor aproveitamento destes resíduos de forma a torná-los indispensáveis na cadeia produtiva.

A principal limitação do estudo está associada ao uso somente de dados secundários para desenvolver esta pesquisa. A realização de entrevistas e aplicação de questionários pode ser enriquecedor e pode ser um motivador para a realização de novos estudos sobre a temática em voga. Recomenda-se em estudos futuros que sejam feitas pesquisas relacionadas a possibilidade de novas ações de parceria para o aumento da coleta dos pneus em nosso país; assim como, o comparativo das práticas brasileiras a práticas de outros países.

\section{SUSTAINABLE DISPOSAL OF SCRAP TIRES}

\begin{abstract}
This research aims to approach the process of collecting and recycling waste tires in Brazil, along with the verification of the actions developed by the tire manufacturers after the creation of the National Solid Waste Policy. It also aims to verify the evolution of the percentage of recycled tires and the role of collection points to the growth of this economic sector. The theoretical foundation was built based on concepts and characteristics of sustainability, along with the current legislation on the subject and interrelating them with the reverse logistics of waste tires in Brazil over the years. The methodology was developed from a case study of Reciclanip company, addressing the company's participation in the tire recycling growth and also to carry out an analysis of the importance of collecting points for compliance with current legislation. The results show that there was an increase in the percentage of recycled tires in Brazil since the establishment of the National Solid Waste Policy (PNRS). The collection process starts at 824 points and recycling process
\end{abstract}


comprises the steps of co-processing, laminating, creating rubber products and rubber asphalt. In 2013 Brazil reached $95 \%$ of the target established for proper disposal of scrap tires. The goal that had been set was the collection of $479,429.60$ tons of tires and finding an allocation of 459,030.18 tons. Therefore, we conclude that there is an awareness and an improvement in the indicators concerning the matter, and these can be associated with Law No. 12,305 / 10, establishing PNRS.

Keywords: Sustainability. Reverse logistic. Sustainable disposal.

\section{REFERÊNCIAS}

AMBIENTE BRASIL. Reciclagem de Pneus. Disponível em: <http://ambientes.ambientebrasil.com.br/ residuos/reciclagem/reciclagem_de_pneus.Acessado em: 8 jul. 2015.

ASSOCIAÇÃO NACIONAL DA INDÚSTRIA DE PNEUMÁTICOS (ANIP). [2014]. Disponível em: <http://www. anip.com.br/>. Acesso em: 8 jul. 2015.

BERTOLLO, S.A.; FERNANDES JUNIOR, J. L. Benefícios da incorporação de borracha de pneus em pavimentos asfálticos. In: Congresso Interamericano de Engenharia Sanitária Ambiental, 28., Cancun. Anais... Cancun, México: Asociación Interamericana de Ingeniería Sanitaria y Ambiental, 2002.

BRASIL. Resolução n 416 de 30 de setembro de 2009. Brasília, DF: CONAMA, 2009. Disponível em: <http://www.mma.gov.br/port/conama/>. Acesso em: 08 jun. 2015.

BRASIL. Política Nacional de Resíduos Sólidos - Lei n 12.305, 02 de agosto de 2010. [2010]. Disponível em: <http://www.planalto.gov.br/ccivil_03/_ato2007-2010/2010/lei//12305.htm>. Acesso em; 22 jun. 2015.

CHAN, F.T.S; CHAN, H.K.; JAIN, V.A framework of reverse logistic for the automobile industry. International Journal of Production Research, London, UK, v.50, n.5, p. 1318-1331, mar. 2012.

CHEN, C.C. et al. Evaluation of the waste tire resources recovery program and environmental health policy in Taiwan. International Journal of Environmental Research and Public Health, Switzerland. v. 6, n. 3, p. 1075-1094, 2009.

CONSELHO NACIONAL DO MEIO AMBIENTE (CONAMA). Resolução $n^{\circ}$ 258, de 26 de agosto de 1999. [1999]. Disponível em <http://www.mma.gov.br/port/conama/legiabre.cfm?codlegi=258 > Acesso em: 25 jun. 2015.

CONSELHO NACIONAL DO MEIO AMBIENTE (CONAMA). Resolução no 301, de 21 de março de 2002. [2002]. Disponível em <http://www.mma.gov.br/port/conama/legiabre.cfm?codlegi=364 > Acesso em: 25 jun. 2015.

COUNCIL OF SUPPLIER CHAIN MANAGEMENT PROFESSIONAL. Reverse Logistics Definition. [2013]. Disponível em: <http://www.cscmp.org/digital/glossary/glossary.asp>. Acesso em: 25 jun. 2015.

ELKINGTON, J. Canibais com garfo e faca. São Paulo: Makron Books, 2001.

FERREIRA, J. H. M et al. Sistema de Gestão Ambiental ISO 14001 e o Nível de Tratamento de Resíduos sob o enfoque da Produção Verde. In: Encontro de Estudos em Estratégia, 5., Porto Alegre. Anais... Porto Alegre: ANPAD, 2011. 
FREIRE, R. S. et al. Novas tendências para o tratamento de resíduos industriais contendo espécies organocloradas. Química Nova, São Paulo, SP, v. 23, n. 4, p. 504-511, 2000. Disponível em: <http:// quimicanova.sbq.org.br/imagebank/pdf/Vol23No4_504_v23_n4_\%2812\%29.pdf>. Acesso em: 25 jun. 2015.

HORNER, J.M. Environmental health implications of heavy metal pollution from car tires.Rev. Environ. Health, London, UK, n. 11, p.175-178, 1996.

INSTITUTO BRASILEIRO DO MEIO AMBIENTE E DOS RECURSOSNATURAIS (IBAMA). Relatório pneumáticos 2013. [2013]. Disponível em:<http://www.ibama.gov.br/phocadownload/.../4?...9649\%3Arelatoriopneumaticos-2013>. Acesso em: 8 jul. 2015.

INSTITUTO BRASILEIRO DE ADMINISTRAÇÃO MUNICIPAL (IBAM). Manual de gerenciamento integrado de resíduos sólidos. Rio de Janeiro: IBAM, 2007.

INTERNATIONAL UNION FOR CONSERVATION OF NATURE AND NATURAL RESOURCES (IUCN). The World Conservation Strategy: Living Resource Conservation for Sustainable Development.Gland. Switzerland: IUCN-UNEP-WWF, 1980.

KWATENG, K. et al. Reverse logistics practices in pharmaceutical manufacturing industry: experiences from Ghana. Global Journal fo Business Research, Hilo, v. 8, n. 5, p. 17-26, 2014.

LAGARINHOS, Carlos A. F.; TENÓRIO, Jorge A. S. Logística reversa dos pneus usados no Brasil. Polímeros, São Carlos, SP, v. 23, n. 1, p. 49-58, 2013.

LEITE, L.; ARAÚJO, J. B.; MARTINS, R. A. Sustentabilidade como direcionador de evolução dos sistemas de medição de desempenho. Navus - Revista de Gestão e Tecnologia, Florianópolis, SC, v. 1, n. 1, p. 35-50, jul./dez. 2011.

MERCADO LIVRE. Cotação de Preço. Disponível em: <http://produto.mercadolivre.com.br/MLB693344211-granulo-de-borracha-grama-sintetica-raspa-atacado-_JM>. Acesso em: 15 fev. 2016.

RESENDE, E. Canal de Distribuição Reverso na Reciclagem de Pneus: Estudo de Caso. [2004]. Disponível em: <http://www.nima.puc-rio.br/cursos/pdf/031_eduardo.pdf>. Acesso em: 28 jun. 2015.

MOLDAN, B.; JANOUAKOVÁ, S.; HÁK, T. How to understand and measure environmental sustainability: Indicators and targets. Ecological Indicators, v. 17, p. 4-13, 2012.

RECICLANIP. Informações da destinação de pneus inservíveis. [2015]. Disponível em: <https://www. reciclanip.org.br/v3/>. Acesso em: 8 jul. 2015.

RODRIGUES, C. M.; HENKES, J. A. Reciclagem de pneus: atitude ambiental aliada à estratégia econômica. Revista Gestão e Sustentabilidade Ambiental, Florianópolis, SC, v. 4, n. 1, p. 448-473, abr./set. 2015.

ROY, J.; NOLLET, J.; BEAULIEU, M. Reverse logistics networks and governance structures. Supply Chain Forum An International Journal, Talence, France, v. 7, n. 2, p. 58-67, 2006.

SARTORI, Simone; LATRÔNICO, Fernanda; CAMPOS, Lucila MS. Sustentabilidade e desenvolvimento sustentável: uma taxonomia no campo da literatura. Ambiente \& Sociedade, São Paulo, SP, v. 17, n. 1, p. 
$1-22,2014$.

TEPPRASIT, Punyapon; YUVANONT, Prangtip. The Impact of Logistics Management on Reverse Logistics In Thailand's Electronics Industry. International Journal of Business and Information, Taipei, v. 10, n. 2, p. 257-271, 2015.

THEYEL, G. Management practices for environmental innovation and performance. International Journal of Operations \& Production Management, Bingley, UK, v. 20, n. 2, p. 249-266, 2000.

WORLD COMMISSION ON ENVIRONMENT AND DEVELOPMENT (WCED). Our common Future. Oxford: Oxford University Press, 1987.

VOTORANTIM. Informações do coprocessamento de pneus inservíveis (2015). Disponível em:<http:// www.votorantimcimentos.com.br/htmsptb/Responsabilidade/Coprocessamento.htm>. Acesso em: 19 jul. 2015. 